\title{
Growth Analysis of Genetically Modified Cassava (Manihot esculenta Crantz) Plants Expressing NPT II Marker and GUS Reporter Genes
}

\section{Jelili T Opabode*}

Department of Crop Production and Protection, Obafemi Awolowo University, Nigeria

Submission: November 21, 2017; Published: March 12, 2018

"Corresponding author: Jelili T Opabode, Department of Crop Production and Protection, Obafemi Awolowo University, Ile- Ife, Nigeria, Email: jopabode@yahoo.com

\section{Abstract}

Background: Cassava is an important root crop with many biotic and abiotic problems. Genetic modification is a viable option for improvement of cassava to against the production constraints.

Objectives: The growth and morphology of cassava transgenic plants modified with NPT II marker and GUS reporter genes andnontransgenic (wild) cassava plants were compared to reveal difference between them.

Method: The study had two experiments: in the first experiment, external morphology and quantitative growth assessment of transgenic and non-transgenic plants were examined. Growth patterns and growth correlations in plants raised from three types of stem cutting were examined in the second experiment.

Results: The external morphology of the transgenic TME 12-2010 were not different from non-transgenic TME 12.However,the shape of the leaf lobe was arched in the transgenic TME 12-2010 but obovate in non-transgenic TME 12. Whether a plant is transgenic or non-transgenic, it had no influence on sprouting percentage, number of sprout per cuttings, leaf area, number of leaf, number of root per plant and total dry weight. However, sprouting percentage, number of sprout per cuttings, leaf area, number of leaf, number of root per plant, total dry weight depended on type of cuttings used as planting materials.Irrespective of types of TME and stem cutting, pattern of growth of stem, leaf, RGR, LAR, NAR and CGR were similar from planting to $8 \mathrm{MAP}$.

Conclusion: Genetic modification of cassava with NPT II and GUS genes caused no growth alterations to the plant and thus, similar agronomic practices should be given to both transgenic and non-transgenic cassava plants.

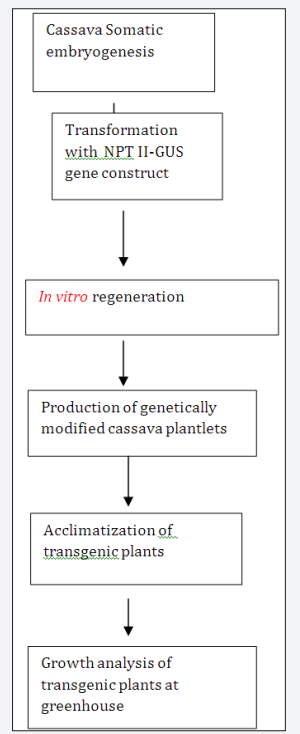

Keywords: Cassava; Genetic modification; Growth; Growth estimate; Marker gene; Reporter gene

Abbreviations: CaMV: Caulifower Mosaic Virus; CsVMV: Cassava Vein Mosaic Virus; CGR: Crop Growth Rate; DWT: Dry Weight; FWT: Fresh Weight; GUS: $\beta$-glucuronidase; LAI: Leaf Area Index; LAR: Leaf Area Ratio;LWR: Leaf Weight Ratio; MAP: Month After Planting; NAR: Net Assimilate Rate; NPT II: Neomycin Phosphotransferase II; RGR: Relative Growth Rate; RLGR: Relative Leaf Growth Rate; T-DNA: Transfer DNA; TME: Tropical Manihotesculenta 


\section{Introduction}

The production of cassava has the potentials of reducing hunger, poverty and food insecurity in developing countries as a result of expansion in the consumption and utilization of the crop [1]. Though cassava originated in South America, it is a staple food for approximately 500 million people in about 105 countries [2]. Cassava is grown primarily for food in Africa whichhas become the largest producer with yields estimated to exceed 160 million tonnes per year In south east Asia, the crop is grown mainly for animal feed and industrial purposes (e.g. sweeteners, acids and alcohols), with increasing interest indeveloping cassava for biofuel [3]. However, there are numerous challenges affecting production and utilization of cassava. Among these problems are weeds, pests, diseases, postharvest deterioration of tubers, low qualities of starch, drought, cold, salinity, extreme temperatures to mention but a few [2]. Applications of conventional breeding techniques achieved limited success because the crop is vegetatively propagated, highly heterozygous and limited seed setting [4]. A viable alternative for genetic improvement of cassava against biotic and abiotic stresses is genetic transformation by recombinant DNA technique [5]. It was against this background that we set up Cassava Improvement Programme.Our work has produced a transgenic TME 12 cassava plant, TME 12-2010, which carried a T-DNA vector with CsVMVGUS and CaMV35S -NPTII cassettes transcribing in the opposite direction [6]. The vector was introduced into the cassava genome by Agrobacterium tumefaciens strains LB4404.

Selectable and screenable markers are co-transformed into cassava tissue to serve different and important purposes [7]. A common selectable marker being utilized for cassava genetic transformation is neomycin phosphotransferase II (NPT II). The NPT II was isolated from the Tn5 transposon of Escherichia coli (Migula) Castellani and Chalmers [8]. The NPT II catalyses the transfer of the -phosphate group of Adenine Triphosphate to the 3'- hydroxyl group which prevents the antibiotic from bindingto the 30s ribosomal subunit and thus inhibits protein synthesis [9]. The NPT IIgene confers resistance to the antibiotics: kanamycin, paromomycin and G418 [10]. In plant genetic transformation studies, NPT-II marker is used for selection of transformed cells or tissue explants by their ability to grow in the presence of the antibiotics $[10,11]$. In addition, they are used to follow the inheritance of foreign genes in a segregrating population of transgenic cassava plants. The most frequently used screenable marker or reporter gene in the development of transgenic cassava plants is $\beta$-glucuronidase (GUS) gene [7]. $\beta$-glucuronidase was isolated from $E$. coli $\mathrm{K} 12$. $\beta$-glucuronidase catalyses the hydrolysis of glucuronides.The GUS marker gene is included in many transformation vectors for several purposes:to allowfor visualization of the cells, tissues or explants expressing the foreign gene;to develop and monitor plant transformation processes; to assess transient and stablegene expression levels and to follow the integrated trait in breeding programs [7]. Furthermore, GUS marker is used to know the temporal and spatial expression pattern of the foreign gene [7,12]. Ouakfaoui \& Miki [13] reported no phenotypic or genetic expression changes of 24,000 genes in transgenic Arabidopsis plants containing the GUS and NPT II genes.

Growth analysis and pattern in non-transgenic cassava plants have been documented [14-16]. Growth in non-transgenic cassava plants has two phases: before and after onset of root thickening (bulking) $[14,15]$. Crop growth rate in non-transgenic cassava plants is positively correlated to relative growth rate, leaf area ratio, leaf area index, leaf weight ratio and dry weight [16]. Transgenic cassava plants have been developed expressing NPT II and GUS genes in various tissues and organs $[6,10,11,17,18]$. However, detail growth and morphological analyses have not been conducted on the transgenic cassava plants. Growth studies become essential as some transgenic crops that contain NPT-II and GUS in their T-DNA vector, in addition to agronomic traits, have been reported to display slower growth than the non-transgenic ones [19]. Similarly, co-existence of markers in transgenic plants for a long period has been reported to be interfering with the growth and development processes of transgenic plants [20]. In this study, growth analysis of TME 122010, a transgenic cassava plant containing a transformation vector which carried NPT-II and GUS genes asselectable marker and scorable reporter genes, respectively [6] was conducted. The objectives of the study were to (a) examine morphological and growth differences between transgenic TME 12-2010 and nontransgenic TME 12 cassava plants at six weeks after planting and (b) conduct growth analysis on the transgenic plants raised from three types of stem cuttings obtained from plants at sixth cycle of vegetative propagation.

\section{Materials and Methods}

\section{Plant materials and growth conditions}

The study was conducted at the screen house of the Faculty of Agriculture, ObafemiAwolowo University, Ile-Ife, Nigeria. IleIfe is located on $07^{\circ} 28^{\prime} \mathrm{N}, 04^{\circ} 33^{\prime} \mathrm{E}$ at $255 \mathrm{~m}$ above sea level. Two types of cassava variety TME 12 were used for the study: TME 12 and TME 12-2010. TME 12 was the non-transgenic (wild) TME 12 while TME 12-2010 was the transgenic plants derived from TME 12.The transgenic cassava plants carried a T-DNA vector with CsVMV-GUS and CaMV 35SNPTII cassettes transcribing in the opposite direction [6]. The vector was introduced into the cassava genome by Agrobacterium tumefaciens strains LB4404. The study involved two experiments: (a) morphological and quantitative growth analyses of transgenic TME 12-2010 and non-transgenic TME-12 plants and (b)Influence of TME 12 type and cutting type on growth pattern of cassava plants.

\section{Experiment 1: Morphological and quantitative growth analyses of transgenic TME 12-2010 and non- transgenic TME-12 plants}

The objective of this experiment was to examine morphological differences between transgenic TME 12-2010 and 
non-transgenic TME 12 cassava plants. Hardened and vigorous 42-day-old in vitro plantlets of TME 12 and TME 12-2010 were obtained from Cassava Genetic Transformation Programme, Central Biotechnology Laboratory, International Institute of Tropical Agriculture (IITA), Ibadan, Nigeria. Each plantlet $(10 \mathrm{~cm}$ in height) was planted in a plastic pot $(30 \mathrm{~cm}$ diameter, $40 \mathrm{~cm}$ deep) containing $10 \mathrm{~kg}$ sieved sandy loam soil. The soil had a $\mathrm{pH}$ of $5.8,0.43 \%$ organic $\mathrm{C}, 0.065 \% \mathrm{~N}$ and $4.2 \mathrm{mg} / \mathrm{kg}$ extractable Bray1 P. Randomized complete block design with three replicates was used for the study. There were fifty plants per treatment. Plants were watered manually to field capacity daily.

As from four weeks after planting, observations were recorded on morphologically characters such as external stem colour, colour of fully expanded leaves, petiole colour, colour of leaf vein, presence of stipule, leaf lobe shape, leave arrangement, root type and external root clour with the aim of distinguishing between transgenic and non-transgenic cassava variety TME 12 . Data were also recorded on leaf area, internode length, petiole length, root and shoot dry weight at four and eight weeks after planting. Five plants were selected from each TME types for each harvest. At each harvest, plants were separated into leaf, petiole, stem and root. The underground portions were recovered by washing in water. Plant parts were separately dried in an electric oven at about $75{ }^{\circ} \mathrm{C}$ for 48 hours till they reached constant weight. Leaf area was measured with a photoelectric planimeter (Lambda Mod. 3050 A, UK).Data were subjected to analysis of variance and T- test was used to separate means at $5 \%$ level of probability level [20].

\section{Experiment 2: Influence of TME 12 type and cutting type on growth pattern of cassava plants}

Plants were raised from stem cuttings of plants that have undergone six cycles of vegetative propagation. Each cutting (4cm long) was planted in a plastic pot $(30 \mathrm{~cm}$ diameter, $40 \mathrm{~cm}$ deep) containing $10 \mathrm{~kg}$ sieved sandy loam soil. The soil had a $\mathrm{pH}$ of $5.8,0.43 \%$ organic C, $0.065 \% \mathrm{~N}$ and $4.2 \mathrm{mg} / \mathrm{kg}$ extractable Bray-1 P. Randomized complete block design with three replications was used for the study. The experiment had two factors: TME 12 types (transgenic vs non-transgenic) and stem cutting types (hardwood, semi-hardwood and softwood). There were fifty plants per treatment. Plants were watered manually to field capacity daily. For growth analyses, six harvests were taken at equal intervals of 30 days. Three plants were selected for each variety from each treatment for each harvest. The first harvest was taken at 30 days after planting (DAP). At each harvest, plants were separated into leaf, petiole, stem and root. The underground portions were recovered by washing in water. Plant parts were separately dried in an electric oven at about $75^{\circ} \mathrm{C}$ for 48 hours till they reached constant weight. Leaf area was measured with a photoelectric planimeter (Lambda Mod. 3050 A, UK).The curvefitting method (functional technique) was followed to determine different growth attributes as outlined by Evans 1972 and applied to cassava by San Jose \& Mayobre [15]. In this method, polynomial functions were fitted to natural logarithmic values of total dry weight and total leaf area. The loge transformation was made in order to render the variance homogeneous with time [21]. The selection of appropriate polynomial regression model was done by "lack of fit" method of Nicholls and Calder [22]. The growth estimates calculated included crop growth rate (CGR), net assimilate rate (NAR), leaf area ratio (LAR), relative growth rate (RGR), leaf area index (LAI), leaf weight ratio (LWR) and relative leaf growth rate (RLGR). Data were subjected to analysis of variance. Growth patterns for eight months were presented using Microsoft Excel software. Simple correlation coefficients among growth attributes were calculated for plants raised from hardwood cuttings at 8 MAP.

\section{Results}

\section{Morphological and quantitative growth analyses of transgenic TME 12-2010 and non-transgenic TME-12 plants}

Table 1: Morphological characteristics of transgenic (TME 12-2010) and non-transgenic (TME 12) cassava plants.

\begin{tabular}{|c|c|c|}
\hline Parameter & TME 12-2010 & TME 12 (control) \\
\hline External stem colour & green & green \\
\hline $\begin{array}{c}\text { Colour of fully } \\
\text { expanded leaves }\end{array}$ & green & green \\
\hline Petiole colour & pink & pink \\
\hline Colour of leaf vein & yellowish pink & yellowish pink \\
\hline Presence of stipule & absence & absence \\
\hline Leaf lobe shape & arched & obovate \\
\hline Leave arrangement & $2 / 5$ phyllotaxis & $2 / 5$ phyllotaxis \\
\hline Root type & fibrous & fibrous \\
\hline External root colour & brown & brown \\
\hline
\end{tabular}

To physically distinguish between transgenic TME 12 and non-transgenic TME 12-2010, their morphological attributes were monitored for eight weeks (Table 1). The external stem colour, colour of fully expanded leaves, petiole colour, colour of leaf vein, presence of stipule, leaf lobe shape, leave arrangement, root type and external root colour of the transgenic TME 122010 were not different from non-transgenic TME 12 . The only different morphological attribute was the shape of the leaf lobe which was arched in the transgenic TME 12-2010 but obovate in non-transgenic TME 12. Quantitative growth measurement of the transgenic TME 12-2010 and non-transgenic TME 12 at eight weeks after planting were presented in Table 2.There were no significant $(\mathrm{P}>0.05)$ differences between the leaf area, stem height, petiole length, average root length, average number of root per plant, root dry weight and shoot dry weight of transgenic and non-transgenic plants.However, significant $(\mathrm{P}<0.05)$ differences were detected in the mean internode length and width of the central lobe of transgenic and non-transgenic plants. Specifically, mean internode length and central lobe width of non-transgenic plants were larger than that of transgenic plants by 50 and $15 \%$, respectively.Moreover, the range of values of stem height, central lobe width, average root length, root dry weight, average 
number of root and shoot dry weight of non-transgenic plants were greater than that of transgenic plants. However, leaf area,

mean internode length and petiole length of transgenic plants exhibited higher range of values than non-transgenic plants.

Table 2: Growth characteristics of pot-grown transgenic (TME 12-2010) and non-transgenic (TME 12) at eight weeks after planting.

\begin{tabular}{|c|c|c|c|c|c|c|c|}
\hline Parameter & \multicolumn{3}{|c|}{ TME 12-2010 } & \multicolumn{3}{c|}{ TME 12 (Control) } & Ttest (0.05) \\
\hline & Mean & Range & SE & Mean & Range & SE & NS \\
\hline Leaf area (cm2) & 8.2 & $7.8-8.4$ & 0.34 & 8 & $7.7-8.1$ & 0.21 & 0.28 \\
\hline Stem height (cm) & 7.5 & $8-10$ & 0.23 & 7.8 & $7-12$ & NS \\
\hline Number of lobe/leaf & 2.3 & $2-3$ & 0.16 & 3.5 & $4-5$ & 0.17 & NS \\
\hline Mean internode length (cm) & 1.8 & $1-3$ & 0.32 & 2.7 & $2.4-5.1$ & 0.25 & $2.2^{*}$ \\
\hline Width of central lobe (cm) & 2 & $1.5-2.2$ & 0.61 & 2.3 & $1.3-5.3$ & 0.82 & $0.8 *$ \\
\hline Petiole length (cm) & 6.8 & $6-9$ & 0.25 & 6.6 & $5-7$ & 0.21 & NS \\
\hline Average root length/plant (cm) & 8.4 & $8.0-8.7$ & 0.08 & 8.5 & $7.8-8.6$ & 0.21 & NS \\
\hline Root dry weight/plant (g) & 4.4 & $4.1-4.5$ & 0.31 & 4.8 & $3.8-6.4$ & 0.35 & NS \\
\hline Average number of root/plant & 7.2 & $6.8-7.6$ & 0.07 & 7.5 & $5.3-10.8$ & 0.09 & NS \\
\hline Shoot dry weight (g) & 12.4 & $12.6-12.9$ & 0.06 & 13.8 & $10.6-15.5$ & 0.42 & NS \\
\hline
\end{tabular}

* = significant at $\mathrm{P}=0.05, \mathrm{NS}=$ not significant at $\mathrm{P}=0.05$

\section{Influence of types of TME and stem cuttings on growthof cassava plants}

Analysis of variance showed that cassava type (transgenic vs non-transgenic) had no effect on sprouting and other parameters measured (Table 3). Moreover, types of stem cutting had influence on leaf area, stem height, RGR, LAR, NAR and CGR (Table 3). Generally, plants raised from hardwood cuttings were higher than those raised from either semi-hardwood or soft cuttings (Figure 1). Irrespective of cassava types and cutting region, the stem growth had the same sigmoidal pattern (Figure 2). In all treatments, stem height increased with age of plants. At 8 MAP, the tallest plants were obtained from hardwood cuttings while the soft cuttings produced the shortest plants. Similarly, leaf area growth of transgenic and non-transgenic plants obtained from the three cuttings types displayed the same patterns: two peaks at 4 and 8 MAP. At 8 MAP, the largest leaf areas were observed on plants raised from hardwood cuttings of transgenic and non-transgenic plants. RGR is the increase in dry matter per unit of original dry matter over a time interval. Also, the RGR had the same pattern in transgenic and non-transgenic plants obtained from the three cutting types with two peaks. The two peaks occurred at 2-3 MAP and 5-6 MAP. The LAR is the ratio of leaf area to dry matter and is an indicator of leafiness of a plant. Furthermore, a uniform mono modal pattern of LAR was observed in all treatments between 3 and 5 MAP. NAR is the rate of increase in dry matter per unit leaf area. The NAR and CGR had similar patterns in both transgenic and non-transgenic plants raised from the three cuttings types. Two peaks of NAR were observed which occurred at 2 and 7 MAP. The only peak of CGR occurred at 7 MAP in all treatments. The highest values of RGR, LAR, NAR and CGR were observed on plants produced by hardwood cuttings. The NAR and RGR exhibited similar trend in the two-phased growth of cassava (Figure 3).

Table 3: Means square of growth parameters as influenced TME 12 and stem cutting types.

\begin{tabular}{|c|c|c|c|c|c|c|c|c|}
\hline SV & DF & Leaf area & Stem Height & RGR & LAR & NAR & CGR & DWT \\
\hline Replicate & 2 & 32.6 & 28.5 & 36.7 & 48.3 & 23.9 & 39.2 & 37.6 \\
\hline TME 12 type (T) & 1 & $137.6^{\mathrm{NS}}$ & $78.4^{\mathrm{NS}}$ & $56.3^{\mathrm{NS}}$ & $79.5^{\mathrm{NS}}$ & $47.9^{\mathrm{NS}}$ & $178.8^{\mathrm{NS}}$ & $88.4^{\mathrm{NS}}$ \\
\hline Cutting (C) & 2 & $234.6^{*}$ & $85.1^{*}$ & $58.2^{*}$ & $87.5^{*}$ & $50.2^{* *}$ & $193.5^{*}$ & $132.1^{*}$ \\
\hline TX C & 2 & $25.2^{\mathrm{NS}}$ & $21.1^{\mathrm{NS}}$ & $18.4^{\mathrm{NS}}$ & $23.4^{\mathrm{NS}}$ & $15.5^{\mathrm{NS}}$ & $21.2^{\mathrm{NS}}$ & $25.7^{\mathrm{NS}}$ \\
\hline Error & 12 & 11.4 & 13.2 & 9.6 & 15.3 & 10.6 & 11.8 & 17.8 \\
\hline R2 & & 0.81 & 0.93 & 0.75 & 0.75 & 0.91 & 0.78 & 0.94 \\
\hline CV (\%) & & 12.2 & 9.2 & 4.5 & 11.5 & 14.6 & 8.9 & 13.4 \\
\hline
\end{tabular}

DF: Degree of Freedom; CGR: Crop Growth Rate; DWT: Dry Weight; NAR: Net Assimilate Rate; LAR: Leaf Area Ratio; RGR: Relative Growth Rate 


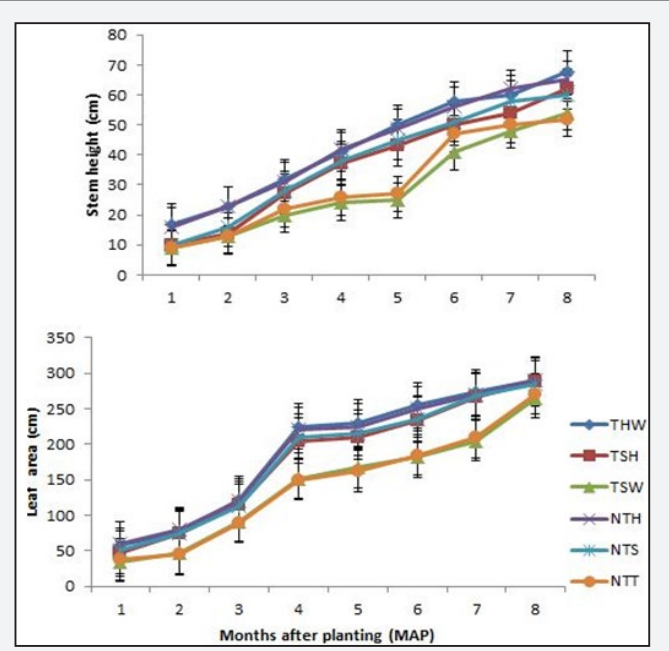

Figure 1: Stem height $(A)$ and leaf area $(B)$ as influenced by stem cutting type in transgenic and non-transgenic plants. THW= transgenic hardwood, THS=transgenic softwood, TSW=transgenic softwood, NTH=non-transgenic hardwood, NTS= non-transgenic softwood, NTT=non-transgenic softwood

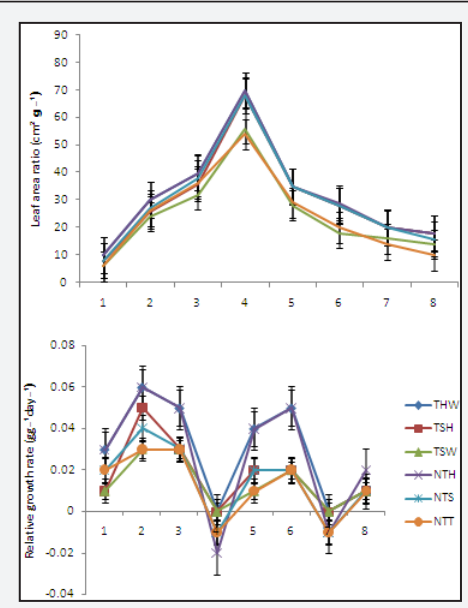

Figure 2: Relative growth rate $(A)$ and leaf area ratio $(B)$ as influenced by stem cutting type in transgenic and non-transgenic plants. $\mathrm{THW}=$ transgenic hardwood, THS=transgenic softwood, TSW=transgenic softwood, NTH=non-transgenic hardwood, NTS= non-transgenic softwood, NTT=non-transgenic softwood

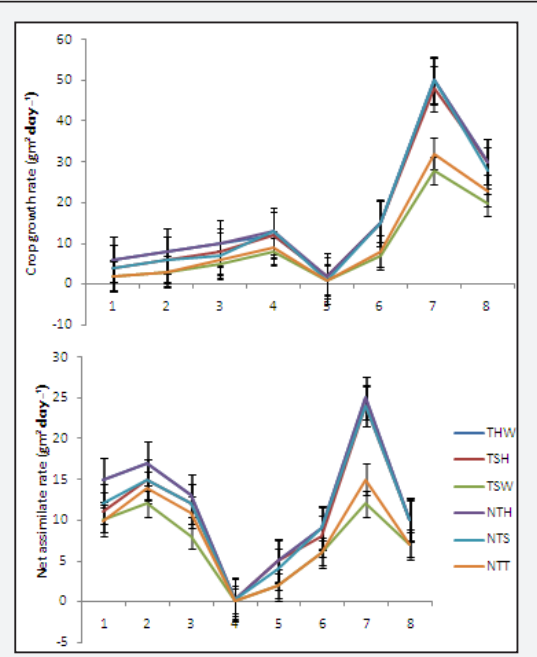

Figure 3: Net assimilate rate $(A)$ and crop growth rate $(B)$ as influenced by stem cutting type in transgenic and non-transgenic plants. THW= transgenic hardwood, THS=transgenic softwood, TSW=transgenic softwood, NTH=non-transgenic hardwood, NTS= nontransgenic softwood, NTT=non-transgenic softwood 


\section{Growth correlations}

Simple linear correlations among growth estimates of transgenic TME 12-2010 and non-transgenic TME 12 plants in experiment 1 (Table 4) were performed to reveal differences in their growth attributes. In both TME 12-2010 and TME 12, CGR had significant $(\mathrm{P}<0.01)$ positive correlations with $\mathrm{RGR}$, LAR, LWR, LAI, FWT, DWT and negatively correlated with RLGR. The RGR, NAR and DWT of TME 12 had higher correlation values with CGR than those of TME 12-2010. Similarly, RGR had significant $(\mathrm{P}<0.01)$ positive correlations with NAR, LAR, RLGR, LWR, DWT and negatively correlated with LAI. However, the values of positive correlation were greater in TME 12 than in TME 12-2010. In both TME 12 types, NAR had significant $(\mathrm{P}<0.01)$ and positive correlations with RLGR, but significant $(\mathrm{P}<0.05)$ and negative correlations with LAI. LAR was significant $(\mathrm{P}<0.05)$ and positively correlated with only DWT but significant $(\mathrm{P}<0.01)$ and negatively correlated with RLGR in both TME 12 and TME 12-2010. Similarly, RLGR had significant $(\mathrm{P}<0.01)$ and negative correlation with LAI in both TME 12 and TME 12-2010. LAI was significantly $(\mathrm{P}<0.01)$ positively correlated to FWT and DWT in both TME 12 types also. Significantly $(\mathrm{P}<0.01)$ positive correlation was established between FWT and DWT of TME 12 and TME 12-2010.

Table 4: Correlation among growth estimates in TME 12 (above) and TME 12 -2010 (below) of plants raised from hardwood cuttings at 8 MAP.

\begin{tabular}{|c|c|c|c|c|c|c|c|c|c|}
\hline Parameter & CGR & RGR & NAR & LAR & RLGR & LWR & LAI & FWT & DWT \\
\hline \multirow[t]{2}{*}{ CGR } & 1 & $0.783^{* *}$ & 0.331 & $0.534^{* *}$ & -0.105 & $0.612^{* *}$ & $0.704^{* *}$ & $0.821^{* *}$ & $0.993^{* *}$ \\
\hline & 1 & $0.513^{* *}$ & 0.231 & $0.534^{* *}$ & -0.105 & $0.612^{* *}$ & $0.824^{* *}$ & $0.821^{* *}$ & $0.863^{* *}$ \\
\hline \multirow[t]{2}{*}{ RGR } & & 1 & $0.880^{* *}$ & $0.515^{* *}$ & $0.455^{* *}$ & $0.548^{* *}$ & -0.061 & 0.343 & $0.534^{* *}$ \\
\hline & & 1 & $0.810^{* *}$ & $0.512^{* *}$ & $0.455^{* *}$ & $0.548^{* *}$ & -0.061 & 0.343 & $0.426^{* *}$ \\
\hline \multirow[t]{2}{*}{ NAR } & & & 1 & -0.041 & $0.853^{* *}$ & -0.031 & $-0.421^{*}$ & 0.126 & 0.234 \\
\hline & & & 1 & -0.041 & $0.823^{* *}$ & -0.031 & $-0.321 *$ & 0.126 & 0.234 \\
\hline \multirow[t]{2}{*}{ LAR } & & & & 1 & $-0.428^{* *}$ & $0.953^{* *}$ & 0.224 & 0.316 & $0.359 *$ \\
\hline & & & & 1 & $-0.428^{* *}$ & $0.953^{* *}$ & 0.224 & 0.316 & $0.359 *$ \\
\hline \multirow[t]{2}{*}{ RLGR } & & & & & 1 & -0.312 & $-0.484^{* *}$ & 0.012 & 0.023 \\
\hline & & & & & 1 & -312 & $-0.454^{* *}$ & 0.012 & 0.022 \\
\hline \multirow[t]{2}{*}{ LWR } & & & & & & 1 & 0.381 & 0.321 & 0.322 \\
\hline & & & & & & 1 & 0.302 & 0.321 & 0.302 \\
\hline \multirow[t]{2}{*}{ LAI } & & & & & & & 1 & $0.587^{* *}$ & $0.621^{* *}$ \\
\hline & & & & & & & 1 & $0.567^{* *}$ & $0.591^{* *}$ \\
\hline \multirow[t]{2}{*}{ FWT } & & & & & & & & 1 & $0.997^{* *}$ \\
\hline & & & & & & & & 1 & $0.991^{* *}$ \\
\hline \multirow[t]{2}{*}{ DWT } & & & & & & & & & 1 \\
\hline & & & & & & & & & 1 \\
\hline
\end{tabular}

** =significant at $\mathrm{P}<0.01 ;{ }^{*}=$ significant at $\mathrm{P}<0.05$

CGR: Crop Growth Rate; DWT: Dry Weight; NAR: Net Assimilate Rate; LAR: Leaf Area Ratio; RGR: Relative Growth Rate; RLGR:

Relative Leaf Growth Rate; LAI: Leaf Area Index; LWR: Leaf Weight Ratio; FWT: Fresh Weight

\section{Discussion}

The NPT II marker and GUS reporter gene are the most frequently utilized marker genes in transformation vector of many transgenic plants, including cassava. Ouakfaoui \& Miki [13] provided molecular evidence the markers caused no alteration in the metabolism and physiology of transgenic plants. In the present study, it is not surprising that no variations were observed in the morphology of transgenic TME 12-2010 and non-transgenic TME 12 except in the shape of leaf lobe. Furthermore, in the present study, mean internode length and central lobe width of non-transgenic plants were larger than that of transgenic plants. Two reasons could be responsible for the observed differences between the transgenic TME 12-
2010 and non-transgenic TME. First, somaclonal variation occasioned by tissue culture work and second, transformationinduced mutation. Wilson et al. [23] provided data to support the occurrence of mutation induced by transformation. Somaclonal variation is a common feature of tissue culture techniques. In cassava, about $1 \%$ somaclonal variations have been observed among regenerated plantlets $[24,25]$. Similar slight variations in leaf morphology in transgenic cassava have been also reported [12]. Transgenic crops that contain NPT-II and GUS in their T-DNA vector, in addition to agronomic traits, have been reported to display slower growth than the non-transgenic ones [19].

Clearly, from the trend of growth estimates, it was obvious that irrespective of cutting types and TME forms from which 
plants were raised, all plants displayed similar bimodal growth pattern. Cassava has been reported to show a bimodal growth rate throughout the season, with a first phase occurring before the appearance of storage roots and the second phase occurs after the formation of tubers [15]. This indicates that the addition of foreign DNA to cassava genome did not alter the natural growth pattern of the resulting transgenic plants. Results revealed that heavy investment was made in leaf area development at the first phase of growth up till 4 MAP after planting and leaf area increment later declined with age. Previous studies revealed that leaf area development in Manihot increases with age up to 6-7 MAP before decline. For example, Williams \& Ghazali [26] observed on Manihotutilissima that leaf area of all the varieties studied approached a maximum after approximately 140 DAP. Similarly, Doku [27] observed that for all the varieties of cassava planted at the onset of rain in March, the number of leaves per plant increased from May to July, after which the growth behaviour of the varieties differed. Begum \& Paul [16] reported that LAR declined steadily with increasing plant age in cassava. Begum \& Paul [16] showed that NAR values decreased at a point at the early stage of growth while it increased up sharply at the later stage of growth in cassava which they attributed to low temperature and rainfall and more susnshine hour. Doku [27] in cassava reported that all the varieties started with high NAR between May and June, fell between June and July, rose again between July and August, thereafter falling between September and October during which period all the varieties except Ankra had negative NAR values. Enyi [14] in cassava reported that NAR value tended to decrease with delay in planting. San Jose \& Mayobre [15] stated that the onset of storage organ development marked a decrease in leaf area at the beginning of tuberization. Later in the season, as tuberization progressed, CGR became generally proportional to NAR. According to Begum \& Paul [16], CGR is positively correlated with RGR, LAR, LWR, LAI, FWT and DWT in cassava. Also, Opas-Boonseng [28] observed positive correlation of CGR and LAI in cassava. In cassava, Doku [27] obtained negative relation between NAR and LAI but OpasBoonseng [28] reported positive correlation. LAR was positively correlated with LWR, LAI, FWT and DWT, and negatively with RLGR. RLGR had negative relation with LWR, and LAI. LWR was positively correlated with LAI, FWT and DWT. Positive relation of tuber yield with LAI was reported in cassava [27].

\section{Conclusion}

This study established that genetic modification of cassava with NPT II and GUS genes caused no growth and morphological alterations to the plant. Furthermore, the study confirmed similar growth pattern in both transgenic and non-transgenic cassava plants and thus, similar agronomic practices should be given to both transgenic and non-transgenic cassava plants. The importance of these findings is that similar agronomic practices (such as planting date, spacings, planting orientation, stem cutting size etc) should be administered to the cultivation of both transgenic and non-transgenic cassava plants.
Generally, there was no difference in the growth and morphology of eight-weeks old transgenic TME 12-2010 and non-transgenic TME plants. However, differences were detected in the shape of the leaf lobe, mean internode length and width of the central lobe of transgenic and non-transgenic plants.In plants raised from stem cuttings after six cycles of vegetative propagation, whether plants is transgenic or not had no influence on growth parameters. However, types of cutting influenced leaf area, stem height, RGR, LAR, NAR and CGR. Also, growth pattern and simple linear correlation among growth estimates in transgenic and non-transgenic plants had similar trends. But, non-transgenic plants had stronger growth correlations than transgenic plants.

\section{Conflict of Interest}

We declare that there are no competing interests between individuals and organizations that can affect the publication of this work.

\section{Aknowledgement}

The author appreciates the contribution of Prof. O.A. Akinyemiju, Faculty of Agriculture, Obafemi Awolowo University.

\section{References}

1. Sanchez T, Salcedo E, Dufour D, Morante N, Debouck D, et al. (2009) Screening of starch quality traits in cassava (Manihot esculenta Crantz). Starch/Starke 61(1): 12-19.

2. Bull SE, Ndunguru J, Gruissem W, Beeching JR, Vanderschuren H (2011) Cassava: constraints to production and the transfer of biotechnology to African laboratories. Plant Cell Rep 30(5): 779-787.

3. Balat M, Balat H (2009) Recent trends in global production and utilization of bio-ethanol fuel. Appl Energy 86: 2273-2282.

4. El-Sharkawy MA (2004) Cassava biology and physiology. Plant Mol Biol 56(4): 481-501.

5. Taylor NJ, Chavarriaga P, Raemakers K, Siritunga D, Zhang P (2004) Development and application of transgenic technologies in cassava. Plant Mol Bio 56(4): 671-678.

6. Oyelakin OO, Opabode JT, Raji AA, Ingelbrecht IL (2015) A Cassava vein mosaic virus promoter cassette induces high and stable gene expression in clonally propagated transgenic cassava (Manihot esculenta crantz). South Afri J Botany 97: 184-190.

7. Petersen W, Umbeck P, Hokanson K, Halsey M (2005) Biosafety considerations for selectable and scorable markers used in cassava (Manihot esculenta Crantz) biotechnology. Environ. Biosafety Res 4(2): 89-102.

8. Beck E, Ludwig G, Auerswald EA, Reiss B, Schaller H (1982) Nucleotide sequence and exact localization of the neomycin phosphotransferase gene from transposon Tn5. Gene 9: 327-336.

9. Miki B, McHugh S (2004) Selectable marker genes in transgenic plants: applications, alternatives and biosafety. J Biotechnol 107(3): 193-232.

10. Schöpke C, Taylor N, Carcamo R, Konan NK, Marmey P, et al. (1996) Regeneration of transgenic cassava plants (Manihot esculenta Crantz) from micro bombarded embryogenic suspension cultures. Nat Biotechnol 14(6): 731-735.

11. Gonzalez AE, Schopke C, Taylor NJ, Beachy RN, Fauquet CM (1998) Regeneration of transgenic cassava plants (Manihot esculenta Crantz) 
through Agrobacterium-mediated transformation of embryogenic suspension cultures. Plant Cell Reports 17(11): 827-831.

12. Schreuder MM, Raemakers CJJM, Jacobsen E, Visser RGF (2001) Efficient production of transgenic plants by Agrobacterium-mediated transformation of cassava (Manihot esculenta Crantz). Euphytica 120(1): 35-42.

13. Ouakfaoui S, Miki B (2005) The stability of the Arabidopsis transcriptome in transgenic plants expressing the marker genes nptII and uidA. Plant J 41(6): 791-800.

14. Enyi BAC (1972) Effect of shoot number and time of planting on growth, development and yield of cassava (Manihot esculenta Crantz). J Hort Sci 47(4): 457-466.

15. San Jose JJ, Mayobre F (1982) Quantitative Growth Relationships of Cassava (Manihot esculenta Crantz): Crop Development in a Savanna Wet Season. Ann Bot 50(3): 309-316.

16. Begum S, Paul NK (2005) Growth analysis of cassava (Manihot esculenta Crantz) varieties in relation to time of planting. Bangladesh. J Bot 34(1): 21-26.

17. Sarria R, Torres E, Angel F, Chavarriaga P, Roca WM (2000) Transgenic plants of cassava (Manihot esculenta) with resistance to Basta obtained by Agrobacterium-mediated transformation. Plant Cell Rep 19(4): 339344

18. Nyaboga EN, Njiru MJM, Tripathi L (2015) Factors influencing somatic embryogenesis, regeneration, and Agrobacterium-mediated transformation of cassava (Manihot esculenta Crantz) cultivar TME14. Frontiers in Plant Sci 6: 411.

19. Vinocur B, Altiman A (2005) Recent advances in engineering plant tolerance to abiotic stress: achievement and limitations. Curr Op Biotech 16(2): 123-132.
20. Kaeppler SM, Kaeppler HF, Rhee Y (2000) Epigenetic aspects of somaclonal variation in plants. Plant Mol Biol 43(2-3): 179-188.

21. Hughes AP, Freeman PR (1967) Growth analysis using frequent small harvests. J Appl Ecol 4(2): 553-560.

22. Nicholls AO, Calder DM (1973) Comments on the use of regression analysis for the study of plant growth. New Phytol 72(3): 571-581.

23. Wilson AK, Latham JR, Steinbrecher RA (2006) Transformationinduced mutations in transgenic plants: Analysis and biosafety implications. Biotech Gen Eng Rev 23: 209-226.

24. Opabode JT, Oyelakin OO, Akinyemiju OA, Ingelbrecht IL (2013) Primary somatic embryos from axillary meristems and immature leaf lobes of selected African cassava varieties. British Biotech J 3(3): 263273.

25. Opabode JT, Oyelakin OO, Akinyemiju OA, Ingelbrecht IL (2014) Influence of the source and age of explants on secondary and cyclic somatic embryogenesis in cassava (Manihot esculenta Crantz). British Biotech J 4: 254-269.

26. Williams CN, Ghazali SM (1969) Growth and productivity of tapioca (Manihotutilissima). 1. Leaf characteristics and yield. Expl Agric 5(3): 183-194.

27. Doku EV (1965) Breeding for yield in cassava 1. Indices of yield. Ghana J Sci 5: 42-53.

28. Opas-Boonseng (1988) Growth analysis of cassava (Manihot esculenta Crantz). Kasetsart Univ, Bangkok, Thailand, pp. 133.

Your next submission with Juniper Publishers will reach you the below assets

Commons Attribution 4.0 License

DOI: 10.19080/ARTOAJ.2018.14.555921 